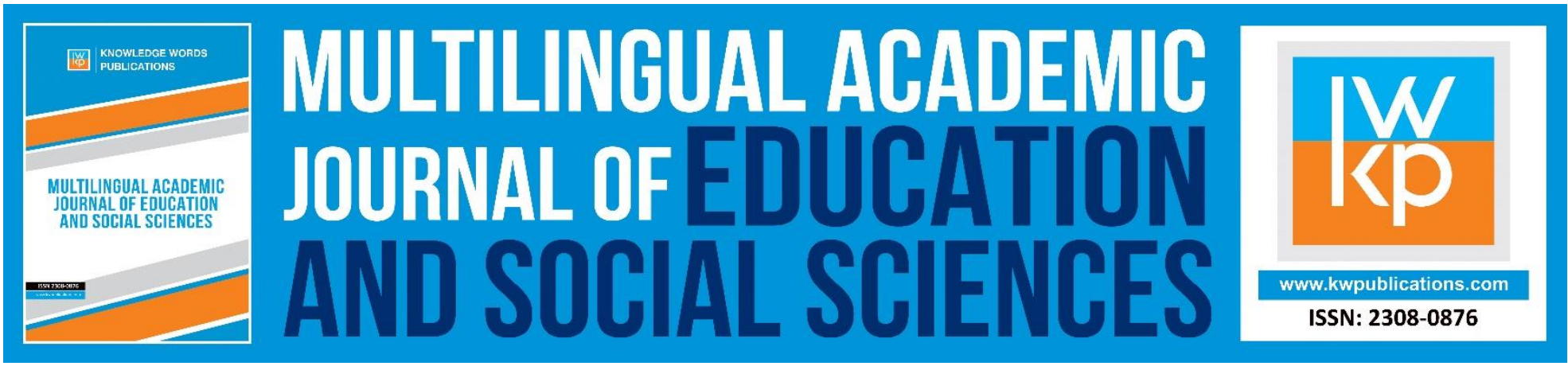

\title{
Controversy of Self versus People Perception: Revisited
}

\author{
Madhu Pandey
}

To Link this Article: http://dx.doi.org/10.46886/MAJESS/v7-i1/5941

DOI: 10.46886/MAJESS/v7-i1/5941

Received: 14 April 2019, Revised: 02 May 2019, Accepted: 01 June 2019

Published Online: 25 June 2019

In-Text Citation: (Pandey, 2019)

To Cite this Article: Pandey, M. (2019). Controversy of Self versus People Perception: Revisited . Multilingual Academic Journal of Education and Social Sciences, 7(1), 68-76.

\section{Copyright: (C) The Authors 2019}

Published by Knowledge Words Publications (www.kwpublications.com)

This article is published under the Creative Commons Attribution (CC BY 4.0) license. Anyone may reproduce, distribute, translate and create derivative works of this article (for both commercial and non-commercial purposes), subject to full attribution to the original publication and authors. The full terms of this license may be seen

at: http://creativecommons.org/licences/by/4.0/legalcode

$$
\text { Vol. 7, No. 1, 2019, Pg. } 68-76
$$

https://kwpublications.com/journals/journaldetail/MAJESS

JOURNAL HOMEPAGE

Full Terms \& Conditions of access and use can be found at https://kwpublications.com/pages/detail/publication-ethics 


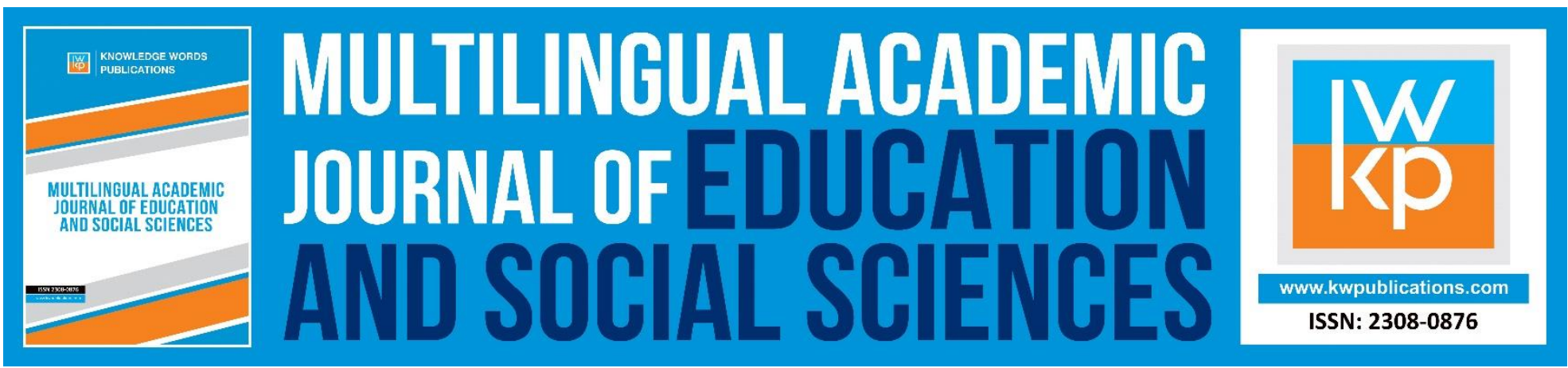

\title{
Controversy of Self versus People Perception: Revisited
}

\author{
Madhu Pandey \\ Department of Psychology, B.S. College, Danapur, Patna \& Joint Secretary, ASSERT, \\ Patna, Bihar
}

\begin{abstract}
A sample of 321 middle class male and female adults having a family participated in a study that aimed to examine whether a social reality can be more accurately constructed by aggregating the self-perceptions of individuals or by pooling their perceptions of the people living around them. Respondents indeed construed their self-more positively, less negatively, and less expedient than of the people around them. However, strong correspondence between self and people perceptions suggested that the controversy about the efficacy of the two methods has been rather exaggerated and that social reality can be explored by either way provided the effects of social desirability from self-perception and stereo typicality from people's perceptions are partial out and data were collected with greater rapport with the respondents.
\end{abstract}

Keywords: Self-Perception, People-Perception, Social Reality, Social Desirability.

\section{Introduction}

There is an ongoing controversy in psychology whether a social reality can be more accurately constructed by asking individual respondents to report how they behave or likely to behave or how they think the people living around them behave or likely to behave in various social situations. The mainstream psychologists subscribed to the formal approach. They were operating under the Western individualist cultural worldview where the society was conceived of the composite of the interacting individuals who know the most about themselves and are capable of articulating what they know. Long back, Cooley (1902) advanced the concept of the "looking glass self". Others (Allport, 1924; Allport, 1968) elaborated it further. Floyd (1924) mentioned that "there is no psychology of groups which is not essentially and entirely a psychology of individuals (p. 4)".

Following this tradition, Edwards (1957) recommends that "if we want to know how individuals feel about some particular psychological object; the best procedure would be to ask them directly (p. 3)", because they were supposed to know accurately and there is no reason why they would not share it with others. The same rationale led by Bem (1972) who argued that self-perception generally follows the same inferential rules as social perception. This similarity leads to parallel inferences about self and others in the face of similar behavioral information. Therefore, people interpret their own behavior rationally in the 
same way they attempt to explain others behavior. The notion that one knows others through the lens of the self is a common-sense idea (e.g., Allport, 1961; Lewis \& BrooksGunn, 1979). Bromley (1978) tried to answer, "the reason why we seem to be able to understand other people (to know what is in their mind; to know what they are inclined to do) is because we tacitly assume they are like us and vice versa (p. 129)". Through early social experiences, individuals formulate a concept of the "generalized other" (Mead, 1934). Following this logic, many researchers (e.g., Hogan, 1975; Hofstede, 1980; Sampson, 1977; Spence, 1985) studied macro level societal phenomena from this individualistic perspective. One of the most famous among them was Hofstede who aggregated the responses of IBM managers from 46 countries to derive four major dimensions on which cultures were compared and contrasted

Despite such a strong tradition of individualistic approach of self-reported evidence for constructing social reality, there were voices of skepticism that started rising in the Western psychology. It was found that individuals are not always totally objective and biasfree in reporting about themselves. There are individuals who tend to twist their responses towards presenting a more socially desirable image of themselves in order to seek other's approval (Crowne \& Marlowe, 1964). This 'self-serving biases' was noticed particularly by those psychologists who were sensitive to cultural factors. Triandis (1980), for example, cautioned that self-reporting individuals are more likely to distort their responses so that they will appear to be socially desirable people (p. 80).

If social desirability affects self-perception, its effects are likely to be more pronounced in a collectivist culture of India (Hofstede, 1980; Sinha \& Verma, 1987). In a collectivist culture, people identify with their in-groups, conform to social norms, seek to achieve collective's goals, and relish approval and appreciation from relevant others (Triandis, 1995). Naturally, they are likely to be more prone to present themselves as socially desirable. Hence, Sinha (2010) conducted a number of empirical studies to provide an alternative method to construct social reality. He argued that a social collective is not the sum total of its individuals; it has an entity of its own. Hence, respondents should be asked to focus on the social entities as they exist in the social domain and identify and rate its attributes. Focusing on a social entity is likely to allow the respondents to distance from their own dispositions and thereby keep their perceptions less contaminated by social desirability. Further, it requires a fewer respondents to construct the social reality and thus relieves psychologists from the chronic problem of getting a representative sample. He drew on the anthropological tradition (Bernard et al., 1984; Campbell, 1955; Mead, 1934, among others) where a few informants enabled a researcher to develop the profile of ethnic groups outside of Western hemisphere. However, such ethnic profiles were alleged to be marked by sweeping generalizations. The image of a reality that is developed by such a method seems to be stereotypical where the informants go more by the hearsay than their actual perceptions or firsthand experiences.

Furthermore, informants are likely to be prone to detect more negative than positive characteristics of a collective (Berkowitz, 2004). Sinha indeed delineated many negative attributes of Indians. He and his associates in a number of studies (reviewed in Sinha, 2010) reported that Indians are power hungry, status conscious, money minded, and so on. A study in which data were collected from 12 locations in India by 14 authors (Sinha, et al., 2010) showed that duplicity is the most dominant feature of Indians. Duplicity means that Indians profess to be ideal, honest, reliable friends, freedom loving, peace seeking, etc., but often behave contrary to what they profess (pp. 6-7). Two other studies (Sinha, 2012; Sinha \& 
Hassan, 2014) also found that Indian respondents often attribute positive characteristics more to themselves than others who are perceived to have more of negative characteristics.

In sum, both - self-perception and people perception - methods have potentials as well as limitations. It is imperative to compare them in one study in order to see their relative efficacy. This was made possible in course of a larger research project (Pandey, 2012) on the evolving nature of the Indian middle class mentality. The present study utilizes part of the data for throwing light on the issue.

\section{Method}

\section{Participants}

The sample comprised of 321 respondents of Patna (India) including males (60.55\%) and females (39.45\%). Their age ranged from 21 to 77 years, the average falling around 46 years $(S D=0.76)$. All of them were married and had a family including children. Majority of respondents $(37.10 \%)$ came from villages followed by small cities $(32.40 \%)$ and the capital city Patna (30.50\%). A small number of them (7.40\%) had education up to the secondary school level, 40.90 per cent were graduates, 41.30 per cent were post graduates and remaining 10.40 per cent had higher level education. Further, 47.20 per cent were government employees, 14.90 per cent were in private companies, 12.70 per cent in business, 11.40 per cent in practices, 10.60 per cent home makers and 3.20 per cent in other professions. All of the respondents were of middle class in terms of socio- economic status.

\section{Measures}

The measures were developed in different stages. First of all, a sample of 45 middle class male and female adults in Patna were approached individually for sparing some time for the research, made comfortable with small talks explaining the purpose of research, and then asked in an open-ended interview format to brainstorm and freely express what the people in the society most often believe, prefer, and practice. Once they finished expressing their ideas, then they were asked to tell about themselves: What they most often believe, prefer, and practice. A large number of statements were collected in both formats: informants of peoples' and their own beliefs, preferences, and practices. The statements were thoroughly discussed within the seminar of ASSERT Institute of management studies (Patna) before they were selected for constituting the questionnaire for the main study. There were common as well as different statements for self and people perception. Of them, 22 statements were common in both - self and people - formats. The common statements constituted the measure for the present study of them 11 were expedient, nine negative and two positive. The items were in Hindi and were phrased as statements soliciting the respondents to rate them on a 4-point Likert scale ranging from Quite True (4), True (3), False (2), to Quite False (1).

A biographical inventory was developed for eliciting respondent's gender, age, education, occupation, perceived class status, and whether they spent most of their growing years in a village, small town, or big city etc.

\section{Procedure}

Respondents were approached individually, explained the purpose of the study, and were requested to suggest some time convenient to them for an interview. Few minutes were spent in small talks to put them at ease before they were requested to read and rate each statements on 4-point scale by marking a tick on the correct alternative. They were told that 


\section{MULTILINGUAL ACADEMIC JOURNAL OF EDUCATION AND SOCIAL SCIENCES}

Vol. 7 No. 1, 2019, E-ISSN: 2308-0876 @ 2019 KWP

there was no right or wrong answer and what they thought were the only right answers. Hence, they were impressed upon to rate each of the statements without any hesitation or misgiving. The self and others format of the questionnaires were randomized before presentation.

\section{Results}

The mean and SD scores for each of the items were computed separately for the self and people format. A paired-comparison t-test was computed to see the significance of mean differences. Coefficients of correlation between the self and people perceptions were also computed for each of the statements. The findings were shown in Table 1.

Table 1. Mean, SD., Coefficients of Correlation, and t-test of Perception of People and Self

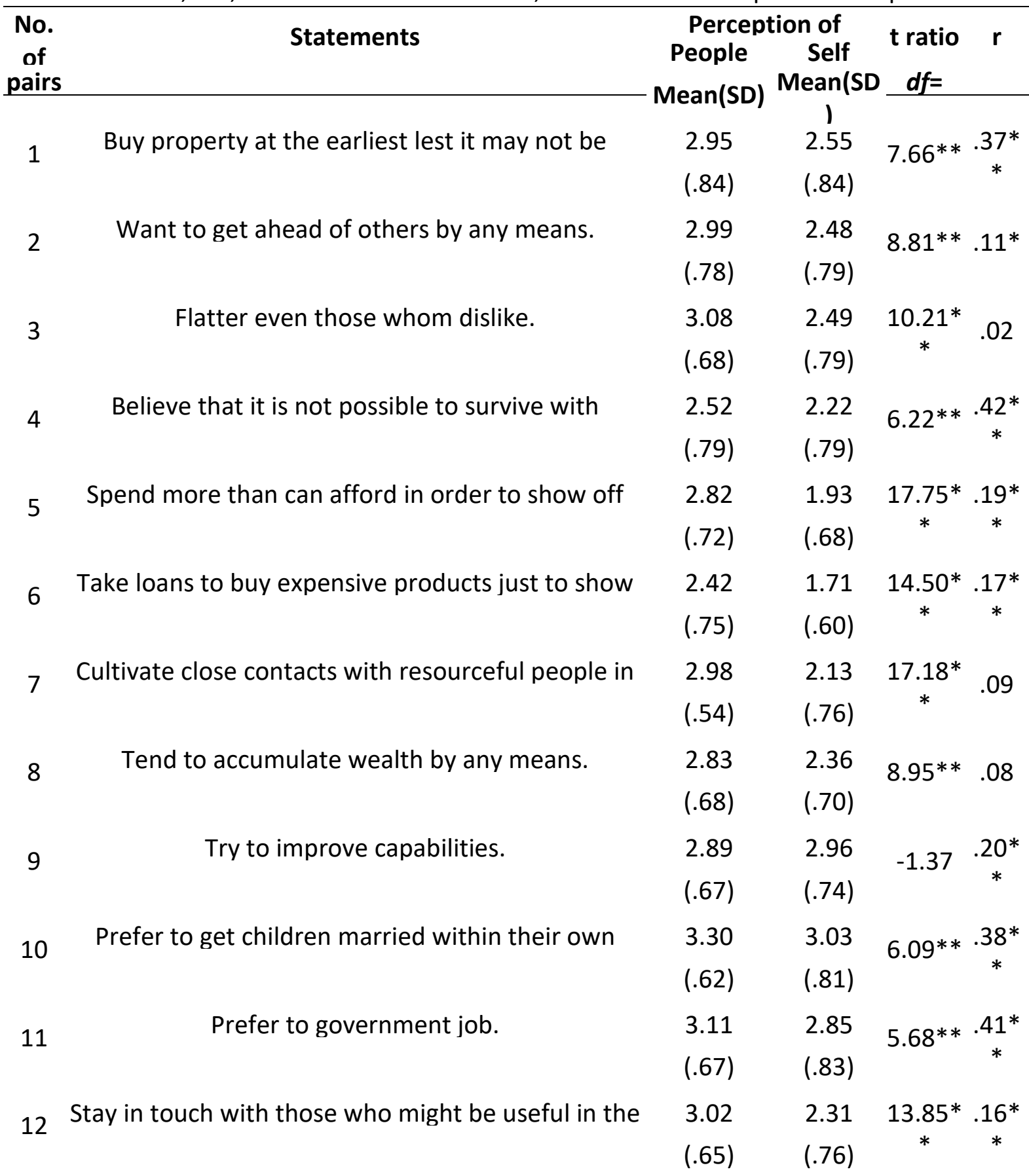


MULTILINGUAL ACADEMIC JOURNAL OF EDUCATION AND SOCIAL SCIENCES

Vol. 7 No. 1, 2019, E-ISSN: 2308-0876 @ 2019 KWP

13

14

15

16

17

18

19

20

21

22

Prefer to associate with the rich and famous by way

2.80

Feel concerned about health problem or mishap in

2.88

Worry about landing in some serious trouble.

Worry that children might lag behind others in

Worry that children might neglect traditions.

2.86

2.91

Cultivate relationship expecting to get help when in

Keeps proximity with resourceful person expecting

3.01

3.07
$2.2311 .75^{*} .16 *$

2.62

2.93

2.73

2.72

2.77

2.42

$7.80 * *$
$.16 *$
$*$

$-0.74 .37 *$

$2.43 * .42 *$

$7.33^{* *} \cdot .35^{*}$

$2.34 * .35 *$

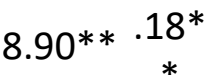

2.20

$18.09 * .21 *$

$10.24^{*}$
$*$

2.57

$11.79 * .41 *$

Note. The items were originally in Hindi. Ratings were on a 4-point scale.

$* * p<.01 ; * p<.05$.

Table 1 showed that out of 22 pairs of mean scores, 20 were significantly different. The two statements on which the differences were not significant were positive in nature as (a) try to improve capabilities and (b) feel concerned about health problem or mishap in family. On both of them, the mean scores of self and people's perception were above the mid-point, however, self-perception ( $M=2.94, S D=.02)$ were higher than those of people's perception ( $M=2.88, S D .01$ ). It showed that they rated both themselves and others high on positive attributes. Remaining 20 significant statements were either negative or expedient. As much as the nine negatively tuned statements were concerned the mean scores of perception of people $(M=2.92, S D=.20)$ were tilted toward the higher side, whereas mean scores of perception of self $(M=2.26, S D=.28$ ) were tilted towards the lower side of the midpoint with two exceptions. Those negative statements indicating that people want to get ahead of others $(p<.01)$, remain friendly even with those whom they dislike $(p<.01)$, spend more than they can afford by way of show off $(p<.01)$, cultivate closer contacts with resourceful people $(p<.01)$, tend to accumulate wealth by any means $(p<.01)$, keep proximity with resourceful person expecting gains from them $(p<.01)$, and indulge in name dropping by associating with resourceful for self- interest $(p<.01)$. However, the respondents thought that neither they nor others take loans just to buy expensive products in order to show off their superiority $(p<.01)$, on the other hand they accepted that they 
and people both preferred to associate with the rich and famous by way of showing own status $(p<.01)$. A common trend was observed in most of the statements that respondents attributed negative orientations to people strongly, but deny their own.

Further, in most of the 11 expedient statements, the mean scores of perception of both - people as well as self ( $\mathrm{M}$ self $=2.59, \mathrm{SD}=.25 \& \mathrm{M}$ people $=2.97, \mathrm{SD}=.20$ ) were higher than midpoint (more than 2.5 at 4 point scale). They were the following: To buy property at the earliest lest it may not be available later $(p<.01)$, prefer to get children married within their own community $(p<.01)$, prefer Government job $(p<.01)$, worry that they might face financial hardship during contingency $(p<.01)$, worry that they might land in some trouble $(p<.01)$, worry that their children might lack behind others in studies and jobs $(p<.01)$, worry that children might neglect own traditions $(p<.05)$. However, the mean scores were higher for people's perception as compared to that of their own. It showed that respondents concede being expedient, but consider people to be more expedient. It may be further noted that out of 22 items, 10 mean self-perception scores were above the objective midpoint (2.50 on 4-point scale) compared to 21 mean scores of the others perception suggesting that respondents were giving higher ratings to people than to self.

The most outstanding finding was the strong correspondence between self and people perceptions, despite the significant mean scores differences between them. Self and people perceptions were significantly and positively correlated on 19 out of 22 statements. The three statements on which they were unrelated were (a) flatter even those whom they dislike $(r=.02)$, cultivate close contacts with resourceful people in order to show superiority $(r=.09)$, and ( $c$ ) try to accumulate wealth by any means. They were most strongly correlated on the statements (a) worry about landing in some serious trouble $(r=.42)$, (b) believe that it is not possible to survive with honesty $(r=.42)$ and (c) prefer to government job $(r=.41)$. The statements on which self and people perceptions are unrelated are largely negative while those on which they are strongly associated were concerned with insecurity in the minds of the middle class adults. They are more expedient than negative in nature.

\section{Discussion}

The study was addressed to the controversy whether individuals' report about their own beliefs, preferences, and practices or their perception about what the people living around them believe, prefer, and practice provide a more effective way to construct a social reality. The first was advocated by Western psychologists (Floyd, 1924; Allport, 1968; Edwards, 1957) and the second by Sinha (2010). Both methods have potentials and limitations. The self-ratings have intuitive appeal as individuals are supposed to know the most about themselves, but are likely to be susceptible to social desirability effects and have the problem of getting a representative sample. The people perception is free of these limitations and is likely to yield a more realistic picture, but is also likely to be stereotypical and is found to generate a largely negative image. The present study has been able to contain the limitations and to highlight their potential. First of all, it was shown that if respondents are put at ease and then requested to generate descriptive statements about themselves and the people around them, they do not only come up with common set of descriptions, but also their descriptions are not always clearly negative. The convergence among them in terms of significant coefficients of correlation was reassuring.

Respondents indeed endorsed the negative or expedient descriptions more for the people around them than to themselves. As the descriptions were by and large either negative or expedient, the findings support Sinha's (2010) contention that social desirability 
does depress the self-ratings and accentuate the people perception. Further, it also shows that people perception tends to be more generalized and may be more stereotypical than actual.

We are never able to get a totally true picture of a social reality. All we can do is to approximate it in varying degrees. The most outstanding strength of the present study is that both methods hold a promise to take us in the same direction, although the levels are statistically significant higher for people perception than for self-perception. The strong correspondence between the self and people perception allows us to predict one from the other. Therefore, people's perception can be estimated from self-perception and vice versa, because either has the potential to approximate social reality. Hence the controversy between the measures of self-perception and people perception is unwarranted.

It may be noted that although Indian culture is found to be by and large collectivist, there are strands of individualistic orientations that coexist with collectivist orientations (Sinha \& Tripathi, 1994; Sinha, et al., 2002).If that is so, there is a round to employ the self-perception method as a viable choice for the domains where social desirability may not look like a strongly interfering factor. Alternatively, a scale of social desirability (such as the one developed by Crowne \& Marlowe, 1964) may be incorporated in the study in order to remove its effects. Similarly, the people perception may be accompanied by a test that partial out respondents' orientation to give stereotypical responses. The present study suffers from the limitations that it did not have such measures included in the design. There was an additional limitation. The respondents reported the descriptions that were largely negative or expedient, not positive. A comprehensive understanding of the merits and demerits of the self and people perception methods will require a set of characteristics that are balanced for being both positive and negative.

\section{References}

Allport, F. H. (1924). Social psychology. Cambridge, MA: Riverside Press.

Allport, G. W. (1961). Pattern and growth in personality. New York: Holt, Rinehart, \& Winston.

Allport, G. W. (1968). The historical background of modern social psychology. In G Lindzey and E Aronson (Eds.), Handbook of social psychology (2nd ed.) 1, 1-80, Reading, MA: Addisson-Wesley.

Bem, D. J. (1972). Self- perception theory. In L. Berkowitz (Ed.), Advances in experimental social psychology, 6,1-62. New York: Academic Press.

Berkowitz, A. D. (2004). The Social Norms Approach: Theory, Research and Annotated Bibliography. New YorK; Perkins \& Linkenbach.

Bernard, H. R., Killworth, P., Kronenfeld, D., \& Sailer, L. (1984). The problem of informant accuracy: The validity of retrospective data. Annual Review of Anthropology, 495517.

Bromley, D. (1978). Natural language and the development of the self. In C. B. Keasey (Ed.), Nebraska Symposium on Motivation 1977: Social and Cognitive Development. University of Nebraska Press.

Campbell, D. T. (1955). The informant in quantitative research. American Journal of Sociology, 60, 339-342.

Cooley, C. H. (1902). Human nature and the social order. New York: Scribner.

Crowne, D. P., \& Marlowe, D. (1964). The approval motive. New York: John Wiley. 
MULTILINGUAL ACADEMIC JOURNAL OF EDUCATION AND SOCIAL SCIENCES

Vol. 7 No. 1, 2019, E-ISSN: 2308-0876 @ 2019 KWP

Edwards, A. L. (1957). The social desirability variable in personality assessment and research. New York: Dryden Press.

Hofstede, G. (1980). Culture's consequences: International differences in work-related values.Beverly Hills, CA: Sage.

Hogan, R. T. (1975). Theoretical egocentrism and the problem of compliance. American Psychologist, 30, 533-540.

Lewis, M., \& Brook-Gunn, J. (1979). Social cognition and the acquisition of self. NY: Plenum. Mead, G. H. (1934). Mind, self, and society. Chicago: University of Chicago Press.

Pandey, M. (2012). The middle class mentality. Research report submitted in Indian Council of Social Science Research (ICSSR), New Delhi, India.

Sampson, E. E. (1977). Psychology and the American ideal. Journal of Personality and Social Psychology, 35, 767-782.

Sinha, J. B. P. (2010). Living and doing psychology. Psychology and Developing Societies, 22(1), 95-120.

Sinha, J. B. P., Singh, S., Gupta, P., Srivastava, K. B. L., Sinha, R. B. N., Srivastava, S., Ghosh, A., Sidiqui, R., Tripathi, N., Gupta, M., Pandey, A., Mulla, Z., \&Vijayalakshmi, C. (2010). An exploration of the Indian mindset. Psychological Studies, 55(1), 3-17.

Sinha, J. B. P., \& Verma, J. (1987). Structure of collectivism. In C. Kagitcibasi (Ed.), Growth and progress in cross-cultural psychology. Lisse, Netherlands: Swets \& Zeitlinger.

Sinha, J. B. P., Vohra, N., Singhal, S., Sinha, R. B. N., \& Ushashree, S. (2002). Normatiuve predictions of collectivist-individualist intentions and behaviour of Indians. International Journal of Psychology, 37(5), 309-319.

Sinha, R. B. N. (2012). Culture- sensitive method for exploring social reality. The Social Engineer, 13(1-2), 80-90.

Sinha, R. B. N., \& Hassan, A. (2014). Respondents versus Informants Method of Data Collection: Implications for Business Research. Multilingual Academic Journal of Education and Social Sciences, 2(1), 1-13.

Sinha, D., \& Tripathi, R. C. (1994). Individualism in a collectivist culture: A case of coexistence of opposites. In U. Kim, H. C. Triandis, C. Kagitcibasi, S. C. Choi, \& G. Yoon (Eds.), Individualism and collectivism: Theory, method, and application (pp. 123-136). Thousand Oaks: Sage.

Spence, J. (1985). Achievement American Style: The rewards and costs of individualism. American Psychologist, 40, 1285-1295.

Triandis, H. C. (1980). Introduction. In H. C. Triandis \& W. W. Lambert (Eds.), Handbook of cross-cultural psychology (Vol. 1). Boston: Allyn \& Bacon.

Triandis, H. C. (1995). Individualism and collectivism. Boulder, Co: West View Press. 